\title{
Existence of Enlarged Parietal Foramina in Bone Collections
}

\author{
Carolina Peixoto Magalhães ${ }^{1}$ Maria Rosana de Souza Ferreira ${ }^{1}$ Rita Santana dos Reis ${ }^{1}$ \\ Fernanda Alda da Silva ${ }^{1}$ Taciana Rocha dos Santos ${ }^{1}$ Renata Cristinny de Farias Campina ${ }^{2}$ \\ ${ }^{1}$ Anatomy, Centro Acadêmico de Vitória, Universidade Federal de \\ Pernambuco, Vitória de Santo Antão, PE, Brazil \\ 2 Anatomy, Universidade Federal de Pernambuco, Recife, PE, Brazil \\ Address for correspondence Carolina Peixoto Magalhães, PhD, \\ Universidade Federal de Pernambuco, Centro Acadêmico de Vitória, \\ Vitória de Santo Antão, PE 55608-680, Brazil \\ (e-mail: monise_moreno@yahoo.com.br).
}

J Morphol Sci 2018;35:125-128.

\begin{abstract}
Introduction The enlarged parietal foramen (EPF) is a defect in the ossification of the parietal bone that is well described in the literature using a variety of nomenclatures. Individuals with EPF can present symptoms such as migraines, vomiting and intense pain when light pressure is applied to the skull. However, it can go unnoticed for a lifetime.

Materials and Methods At the Human Bone Collection department of the Universidade Federal de Pernambuco, 2 craniums (CAV 90, 96 years old and CAV 16, 81 years old) and were identified as having EPF, both from females.

Results There was no apparent kinship between both craniums. The sagittal length, the coronal width, the sagittal suture distance, the coronal suture distance and the lambdoid suture distance of each enlarged parietal foramen were evaluated, with the following results: sagittal length: $5.5 \mathrm{~cm}$ (CAV 90), and $5.0 \mathrm{~cm}$ (CAV 16); coronal width: $3.1 \mathrm{~cm}$ (CAV 90), and $3.4 \mathrm{~cm}$ (CAV 16); sagittal suture distance: $2.9 \mathrm{~cm}$ (CAV 90), and $2.3 \mathrm{~cm}$ (CAV 16); coronal suture distance: $1.8 \mathrm{~cm}$ (CAV 90), and $4.6 \mathrm{~cm}$ (CAV 16); and lambdoid suture distance: $5.0 \mathrm{~cm}$ (CAV 90), and $3.0 \mathrm{~cm}$ (CAV 16). The parietal foramen

Keywords

- cranium

- foramen

- parietal bone

- forensic of both craniums exhibited equivalent measurements.

Conclusion Due to the low incidence of EPF, the identification of the 2 craniums with this condition in a collection of 105 skeletons makes the discovery relevant. In reference to craniums exhibiting EPF, this is an important tool for study and forensic research, since its appearance is linked to heredity.
\end{abstract}

\section{Introduction}

Enlarged parietal foramina (EPFs) are variable intramembranous ossification defects of the parietal bones, first described in 1707 , and which have received little attention until the 1940 s. $^{1,2}$ In normal fetuses, the frontal, parietal, and squamous parts of the temporal bones undergo intramembranous ossification, a direct ossification of the vascularized membrane. Broca, in $1875,{ }^{3,4}$ had already pointed out an unusual enlargement of the parietal foramina due to a failure in the development of the parietal bones. ${ }^{5}$ This neurocranial

received

April 1, 2017

accepted

August 3, 2018

published online

August 31, 2018 abnormality was recently reported in China for a Pleistocene human fossil, Xujiayao 11, which constitutes the oldest evidence in human evolution of this very rare condition. ${ }^{6}$ This defect is known by various names, such as parietal foramina, symmetric parietal foramina, giant foramina parietalia permagna, cranium bifidum occultum and hereditary cranium bifidum.

Enlarged parietal foramina are located in the upper posterior angle of the parietal bone, close to the intersection of the sagittal and lambdoid sutures between the posterior third and the middle third of the sagittal suture, ${ }^{7}$ and appear
Copyright @ 2018 by Thieme Revinter Publicações Ltda, Rio de Janeiro, Brazil
License terms

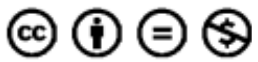


as symmetric, paired radiolucencies on skull radiographs. Enlarged parietal foramina develop as single ossification defects involving both parietal bones followed by a variable reduction in the size of the foramina with the somatic growth during early childhood. ${ }^{8}$

Enlarged parietal foramina may appear without any associated abnormality ${ }^{9}$ or along with associated congenital bone defects, ${ }^{10,11}$ soft tissue pathologies, ${ }^{12}$ an underlying neural deficit, ${ }^{13}$ or as part of a metabolic syndrome. ${ }^{14}$ It may be a variant of cranium bifidum. The condition undoubtedly results from familial inheritance due to the homeobox gene ALX4. ${ }^{15}$ Individuals with EPF have experienced symptoms of violent headaches, vomiting and intense pain on application of mild pressure to the unprotected cerebral cortex. ${ }^{2,16}$

\section{Materials and Method}

The present study was performed with bones from the Human Bone Collection department of Universidade Federal do Pernambuco, state of Pernambuco, Brazil. A total of 75 skulls were examined, of which 40 were male and 35 female. We identified 2 female skulls, 81 and 96 years old, that exhibited signs of EPF. The parameters analyzed were the sagittal and coronal diameters of the EPFs and the distances between the extremities of the foramina and the sagittal, coronal and lambdoid sutures. The measurements were taken with a manual pachymeter with an accuracy of $150 \mathrm{~mm}$. All the procedures for data collection were authorized by the Ethics Committee of the of the Center of Health Sciences of Universidade Federal de Pernambuco (CCS/UFPE, in the Portuguese acronym), under the CAAE number 43228015.0.0000.5208.

\section{Results}

The 2 identified skulls correspond to $2.66 \%$ of the total skulls in the collection. On the CAV90 ( $\mathbf{- F i g . 1}$ ), the right foramen was oval with regular edges, having a $5.34 \mathrm{~cm}$ sagittal diameter, and a $2.99 \mathrm{~cm}$ coronal diameter. It was $3.22 \mathrm{~cm}$ from the sagittal suture, $1.74 \mathrm{~cm}$ from the coronal suture, and $5.25 \mathrm{~cm}$ from the lambdoid suture. The left foramen was oval, having a $5.61 \mathrm{~cm}$ sagittal diameter, and $3.27 \mathrm{~cm}$ coronal diameter. It was $2.50 \mathrm{~cm}$ from the sagittal suture, $1.87 \mathrm{~cm}$ from the coronal suture, and $4.65 \mathrm{~cm}$ from the lambdoid suture (-Table 1$)$.

On the other skull, CAV16 (-Fig. 2), the right foramen was oval with regular edges, having a $5.79 \mathrm{~cm}$ sagittal diameter, and a $3.76 \mathrm{~cm}$ coronal diameter. It was $2.04 \mathrm{~cm}$ from the sagittal suture, $4.44 \mathrm{~cm}$ from the coronal suture, and $2.36 \mathrm{~cm}$ from the lambdoid suture. The left foramen was oval, having a $4.18 \mathrm{~cm}$ sagittal diameter, and a $2.95 \mathrm{~cm}$ coronal diameter. It was $2.46 \mathrm{~cm}$ from the sagittal suture, $4.79 \mathrm{~cm}$ from the coronal suture, and $3.73 \mathrm{~cm}$ from the lambdoid suture (-Table 1).

\section{Discussion}

Enlarged parietal foramina are uncommon structures. However, they are well reported in the literature. ${ }^{17}$ The prevalence of EPF is $1: 15,000$ or $1: 25,000 .^{18}$ Usually, these parts

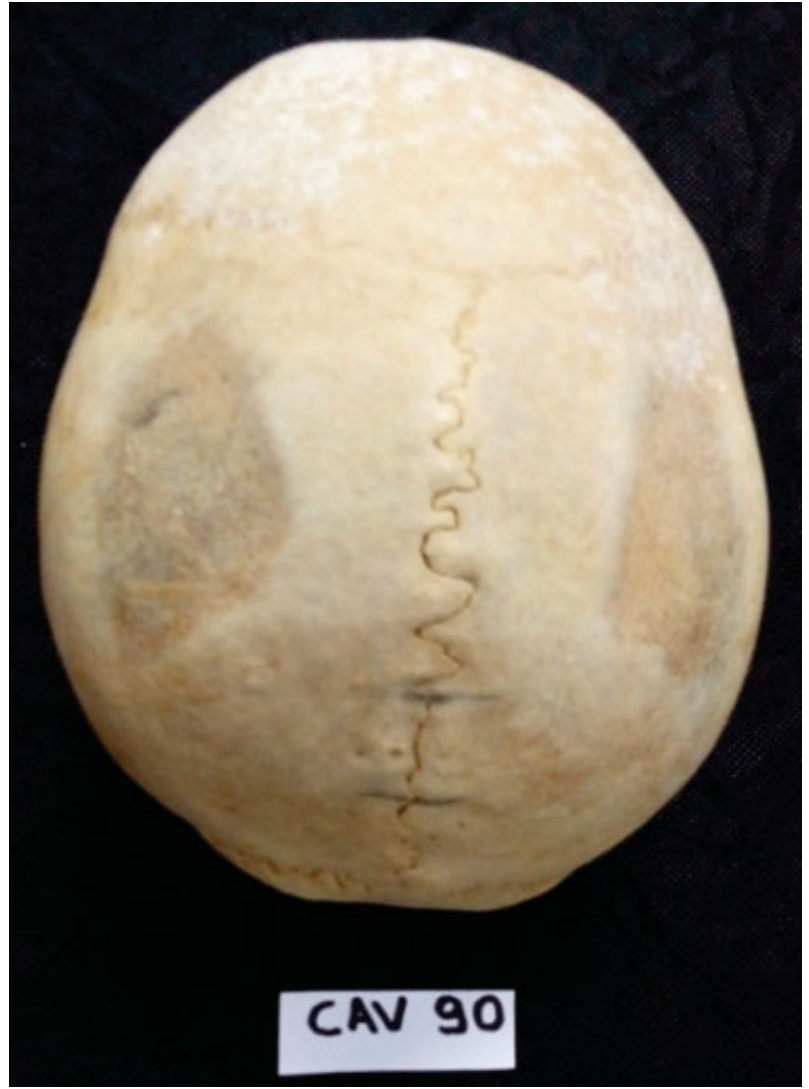

Fig. 1 Female skull, 96 years old, with enlarged parietal foramen.

ossify in the fifth month of gestation. When there is insufficient ossification around the parietal notch, they end up as large permanent foramina. ${ }^{16}$ On cranium CAV16, the EPFs were translucent and of different sizes. At the level of the obelion, ${ }^{19}$ at $2.46 \mathrm{~cm}$ from the lambda, there were two parietal emissary foramina, one on each side of the sagittal suture, the right measuring $0.29 \mathrm{~cm}$, and the left $0.20 \mathrm{~cm}$. Individuals with EPF have a high probability of mutation in the MSX2 or in the ALX4 genes. ${ }^{15}$ The analyzed craniums make it impossible to know the family origin for a possible comparison between them and other members of the family. Most people with EPF have a positive family history, since the condition is inherited in an autosomal dominant fashion with high but incomplete penetrance. ${ }^{16}$ Because it is autosomal dominant, it can help forensic identification once the relatives of the victims are aware of its existence. ${ }^{20}$

On the second cranium, CAV90, the EPFs were not translucent and had different sizes. The average length was $5.0 \mathrm{~cm}$, and the average width was $3.4 \mathrm{~cm}$. Reddy et $\mathrm{al}^{13}$ reported that foramen can be considered enlarged when $>5 \mathrm{~mm}$. Circular, oval, or slit-like EPF measuring several centimeters in diameter or length are rare in the literature. ${ }^{21,22}$ At the level of the obelion, there were 2 parietal emissary foramina, the nearest to the medium sagittal suture with $0.21 \mathrm{~cm}$ and the most lateral with $0.13 \mathrm{~cm}$, both on the left side. The EPF represents a parietal bone ossification anomaly independent of the coexistence of other small parietal foramina on the bone. ${ }^{23}$ The genetic mutation that determines the 
Table 1 Measurements $(\mathrm{cm})$ of the enlarged parietal foramina

\begin{tabular}{|l|l|l|l|l|l|l|}
\hline Cranium & Laterality & $\begin{array}{l}\text { Sagittal } \\
\text { length }\end{array}$ & $\begin{array}{l}\text { Coronal } \\
\text { width }\end{array}$ & $\begin{array}{l}\text { Distance from } \\
\text { the sagittal suture }\end{array}$ & $\begin{array}{l}\text { Distance from the } \\
\text { coronal suture }\end{array}$ & $\begin{array}{l}\text { Distance from the } \\
\text { lambdoid Suture }\end{array}$ \\
\hline \multirow{2}{*}{ CAV90 } & Right & 5.34 & 2.99 & 3.22 & 174 & 5.25 \\
\cline { 2 - 7 } & Left & 5.61 & 3.27 & 2.5 & 1.87 & 465 \\
\hline Average & & 5.5 & 3.1 & 2.9 & 1.8 & 5.0 \\
\hline \multirow{2}{*}{ CAV16 } & Right & 5.79 & 3.76 & 2.04 & 4.44 & 2.36 \\
\cline { 2 - 7 } & Left & 4.18 & 2.95 & 2.46 & 4.79 & 3.73 \\
\hline Average & 5.0 & 3.4 & 2.3 & 4.6 & 3.0 \\
\hline
\end{tabular}

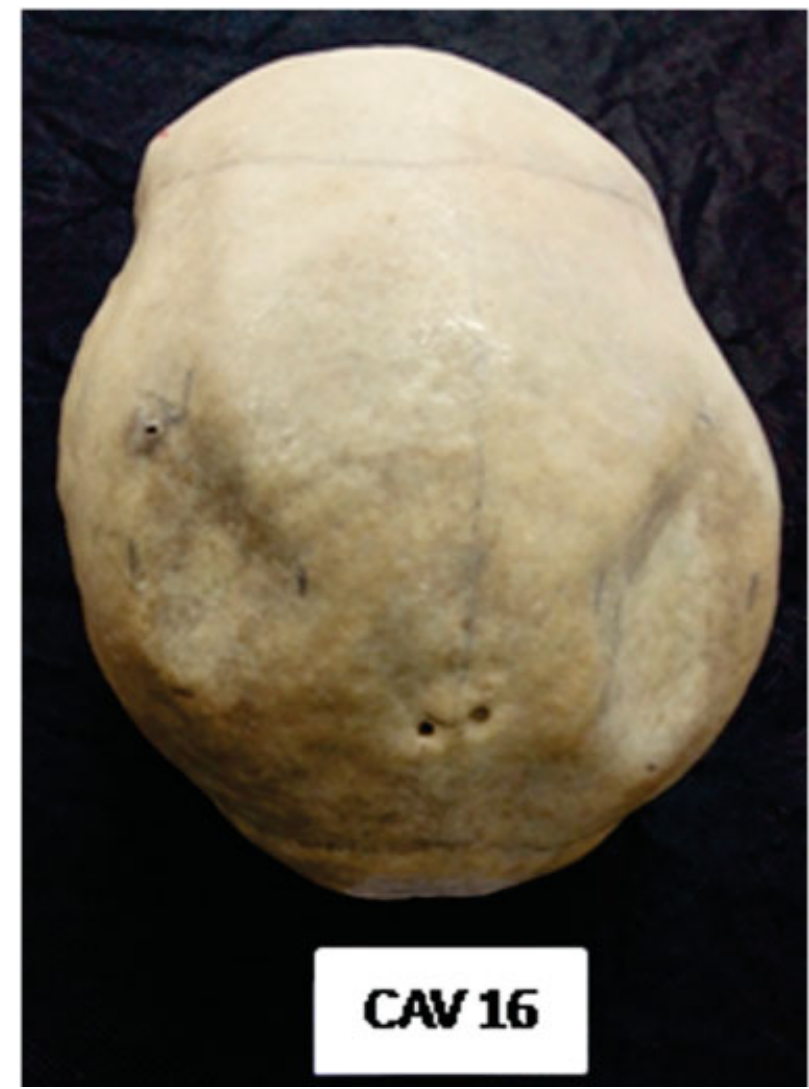

Fig. 2 Female skull, 81 years old, with enlarged parietal foramen.

appearance of EPF occurs due to a defect in the membranous ossification of the cranium, which is directly related to the development of the cranium, face, hair follicles and genitals. ${ }^{24}$ In the two analyzed cases, the EPFs were closed as a result of the growth of the cranium with advancing age. The presence of the EPFs can be associated with other osseous variations and malformations.

\section{Conclusion}

We believe that the description of cases referring to the presence of EPFs in collections of bones can contribute to the forensic research in order to assist in kinship identification, since an EPF is an inherited autosomal dominant congenital malformation. Forensic experts and other researchers need to be aware of these anatomical variations. This type of investigation corroborates the statistics in identifying the frequency with which these foramina currently appear.

\section{References}

1 Halbertsma T. Fenestrae Parietales Symmetricae. Arch Dis Child 1940;15(82):115-120

2 Lodge T. Developmental defects in the cranial vault. $\mathrm{Br} \mathrm{J}$ Radiol 1975;48(570):421-434

3 Broca P. Sur les trous pariétaux et sur la perforation congénitale double et symétrique des Pariétaux. Bull Mem Soc Anthropol Paris 1875;10:326-336

4 Ortner D. 2003Identification of pathological conditions in human skeletal remains. Academic

5 Barnes E. 1994Developmental defects of the axial skeleton in paleopathology. University Press of Colorado

$6 \mathrm{Wu}$ XJ, Xing S, Trinkaus E. An enlarged parietal foramen in the late archaic Xujiayao 11 neurocranium from Northern China, and rare anomalies among Pleistocene Homo. PLoS One 2013;8(03): e59587

7 Freire A, Rossi A, et al. Emissary foramens of the human skull: anatomical characteristics and its relations with clinical neurosurgery. Int J Morphol 2013;31(01):287-292

8 Mupparapu M, Binder RE, Duarte F. Hereditary cranium bifidum persisting as enlarged parietal foramina (Catlin marks) on cephalometric radiographs. Am J Orthod Dentofacial Orthop 2006;129 (06):825-828

9 Pepper O, Pendergrass E. Hereditary occrence of enlarged parietal foramina. Am J Roentgenol Radium Ther 1936;35:1-8

10 Hollender L. Enlarged parietal foramina. Oral Surg Oral Med Oral Pathol 1967;23(04):447-453

11 Mann RW. Enlarged parietal foramina and craniosynostosis in an American Indian child. AJR Am J Roentgenol 1990;154(03): 658

12 Gonzalez-del Angel A, Carnevale A, Takenaga R. Delayed membranous cranial ossification in a mother and child. Am J Med Genet 1992;44(06):786-789

13 Reddy AT, Hedlund GL, Percy AK. Enlarged parietal foramina: association with cerebral venous and cortical anomalies. Neurology 2000;54(05):1175-1178

14 Kayserili H, Uz E, Niessen C, et al. ALX4 dysfunction disrupts craniofacial and epidermal development. Hum Mol Genet 2009; 18(22):4357-4366

15 Mavrogiannis LA, Taylor IB, Davies SJ, Ramos FJ, Olivares JL, Wilkie AO. Enlarged parietal foramina caused by mutations in the homeobox genes ALX4 and MSX2: from genotype to phenotype. Eur J Hum Genet 2006;14(02):151-158

16 Wilkie AOM, Mavrogiannis LA. Enlarged Parietal Foramina. 1993

17 Greig DM. Congenital and Symmetrical Perforation of both Parietal Bones. J Anat Physiol 1892;26(Pt 2):187-191 
18 Collipal E, Silva $\mathrm{H}$, et al. Estudio morfométrico del foramen parietal. Int J Morphol 2009;27(02):481-484

19 Testut L, Latarjet A Anatomía Humana 1971

20 Durão C, Carpinteiro D, Pedrosa F, Machado MP, Cunha E. Enlarged parietal foramina: a rare forensic autopsy finding. Int J Legal Med 2016;130(03):855-857

21 Griessenauer CJ, Veith P, Mortazavi MM, et al. Enlarged parietal foramina: a review of genetics, prognosis, radiology, and treatment. Childs Nerv Syst 2013;29(04):543-547
22 Wysocki J, Reymond J, Skarzyński H, Wróbel B. The size of selected human skull foramina in relation to skull capacity. Folia Morphol (Warsz) 2006;65(04):301-308

23 Currarino G. Normal variants and congenital anomalies in the region of the obelion. AJR Am J Roentgenol 1976;127(03):487-494

24 Chung HY, Uster-Friedberg T, Pentaz S, Blaser S, Murphy K, Chitayat D. Enlarged parietal foramina: findings on prenatal ultrasound and magnetic resonance imaging. Ultrasound Obstet Gynecol 2010;36(04):521-522 